\title{
Metaphor and Metonymy: Making Their Connections More Slippery
}

\author{
John A. Barnden \\ School of Computer Science \\ The University of Birmingham \\ Birmingham, B15 2TT, United Kingdom \\ J.A.Barnden@cs.bham.ac.uk \\ Tel: (+44) (0)121 414-3816 \\ Fax: (+44) (0)121 414-4281
}

\begin{abstract}
This paper continues the debate about how to distinguish metaphor from metonymy, and whether this can be done. It examines some of the differences that have been alleged to exist, and augments the already existing doubt about them. The main differences addressed are the similarity/contiguity distinction and the issue of whether source-target links are part of the message in metonymy or metaphor. In particular, the paper argues that metaphorical links can always be used metonymically and regarded as contiguities, and conversely that two particular, central types of metonymic contiguity essentially involve similarity. The paper also touches briefly on how metaphor and metonymy interact with domains, frames, etc. and on the role of imaginary identification/categorization of target as/under source items. With the possible exception of this last issue, the paper suggests that no combination of the alleged differences addressed can serve cleanly to categorize source/target associations into metaphorical ones and metonymic ones. It also suggests that it can be more profitable to analyse utterances at the level of the dimensions involved in the differences than at the higher level of metaphor and metonymy as such.
\end{abstract}

\section{Keywords:}

Metaphor, metonymy, metaphor/metonymy distinction, contiguity, similarity, part/whole metonymy, representational metonymy, resemblance metaphors, image metaphors

\section{Acknowledgments:}

This research was supported in part by grant EP/C538943/1 from the UK's Engineering and Physical Sciences Research Council (EPSRC), and grant RES-328-25-0009 from the UK's Economic and Social Research Council and EPSRC under the People at the Centre of Communications and Information Technologies programme. I am grateful to colleagues Rodrigo Agerri, Sheila Glasbey, Mark Lee and Alan Wallingon, and to the journal editors and anonymous reviewers, for important suggestions. 


\section{Introduction}

Specifying the nature of metaphor and metonymy has long been a difficult problem. It has been particularly difficult to specify convincing grounds for differentiating the two figures from each other (Barcelona 2000a; Cameron 1999a,b; Dirven and Pörings 2002; Fass 1997; Haser 2005; etc.). The literature exhibits a wide variety of opinion. In this paper we look mainly at two important alleged grounds for differentiation, namely (i) that metaphor involves similarity whereas metonymy involves contiguity or related notions of semantic/pragmatic connection (see, e.g.: Dirven 2002; Jakobson 2002 [1956]; Lodge 1977; Norrick 1981; Nunberg 1978; Riemer 2001; and many others), and (ii) that metonymy preserves links to the source domain item as part of the message whereas metaphor does not (e.g.: Dirven 2002; Haser 2005; Warren 2002). We briefly consider several other issues, including the question of whether metaphor and metonymy interact differently with some postulated structure of domains, frames, idealized cognitive models, or other compartmentalizations of conceptual information.

The paper will conclude that these various possible grounds for differentiation do not, as currently conceived at any rate, provide a firm distinction between metaphor and metonymy. This failure holds even if the putative grounds are combined rather than considered in isolation. The conclusion supports a similar one by Haser (2005: 15), but the paper adds qualitatively new evidence and critique. It leaves it open whether more careful accounts of the alleged differences could lead to a crisp metaphor/metonymy distinction, or whether additional differences could help. Our considerations will also not stop metaphor and metonymy having some tendency to differ in particular ways; with, for instance, metaphor tending to involve a rich form of similarity but metonymy tending not to.

There have been various notions, in the literature, of a cline or spectrum of phenomena incorporating metaphor and metonymy. Radden (2002) makes one such proposal. Dirven (2002) discusses a phenomenon of post-metonymy, intermediate between metaphor and metonymy, although Riemer (2002) argues that (his own version of) post-metonymy need not lead in the direction of metaphor. Croft and Cruse (2004: 220) give examples that suggest intermediate possibilities between metaphor and metonymy, while also warning that what may appear to be intermediacy may be the result of combining distinctly different processes. The present article regards the idea of a spectrum as broadly being on the right track, but pushes the idea further. It doubts that we should think of just a one-dimensional space of possibilities: rather, there are several and perhaps numerous different ways in which metaphor and metonymy can vary in their essence - including variance as regards amounts and types of similarity and contiguity. The positioning of metaphor and metonymy within the space created by these dimensions and others may be very complex.

We will come back to the question of whether there may be intermediate possibilities between metaphor and metonymy in Section 4. Intermediacy is the question whether there are phenomena that have some of the qualities of both metaphor and metonymy but do not qualify as either. For now we focus briefly on the contrasting notion of 
overlap of metaphor and metonymy. Overlap is the question of whether there is a phenomenon that ane and the same time qualifies as being both metaphor and metonymy. We will see that there is evidence of a type of overlap that is distinct from a type that has already been much discussed in the literature. The latter type consists of the sorts of mixing of metaphor and metonymy that have been discussed under the headings of metaphor within metonymy, metonymy within metaphor, chaining of metaphor and metonymy, and so forth (Fass 1997; Goossens 1990; Kövecses 2002; Langlotz 2006; Ruiz de Mendoza Ibáñez and Díez Velasco 2002; Warren 2006). Those types of mixing involve some conceptual item A being linked to some item $\mathrm{X}$, and $\mathrm{X}$ to $\mathrm{B}$, where either the $\mathrm{A}-\mathrm{X}$ link is metaphorical and the X-B link is metonymic, or vice versa. Rather, the type of mixing or overlap addressed in this paper is where an item A is linked to an item B in such a way that qualifies simultaneously as both metaphor and metonymy, but where the situation is not analysable as a chaining of an A-X link and an X-B link. This simultaneity is also to be distinguished from alternativity: the possibility of alternative interpretations of an utterance taking the A-B link to be just metaphorical or just metonymic.

Ritchie (2006: 156) says, in referring mainly to metaphor, "figurative use of language may itself constitute a field of meaning, with dimensions such as conceptuality, opaqueness, literalness, triteness, formality, folkishness among others," and Cameron (1999b) has provided nine dimensions on which metaphor can vary. Many dimensions have been important elsewhere in the literature, such as aptness, vividness, memorability, imageability, evaluativeness, persuasiveness, literariness, social divisiveness/cohesiveness, entrenchedness and cultural specificity. But with the probable exception of literalness, such dimensions arguably do not affect decisions as to whether metaphor or metonymy is involved. The present article is more concerned with dimensions which could be said to be genuinely constitutive of metaphor and metonymy.

Metaphoricity and metonymicity are, arguably, language-user-relative in a deep way. They are affected by such things as the particular lexicon, encyclopaedic knowledge, and interconceptual relationships held by a particular language user (whether utterer or understander). Thus, in principle, an expression should not be said to be metaphorical or metonymic in any absolute sense, but only for a particular user. Of course, in practice, many expressions may be metaphorical or metonymic for the vast majority of native users of a language, and the way in which expressions are metaphorical or metonymic may also be the same or similar across such users (e.g., involve the same conceptual metaphor such as LOVE AS JOURNEY, or the same metonymical schema such as CONTAINER FOR CONTENTS). Relativity has been pointed out by various other authors (Cameron 1999b; Dirven 2002; Geeraerts 2002; Norrick 1981; Pragglejaz Group 2007; Radden 2002; Radman 1997; Riemer 2002; Ritchie 2006; Ruiz de Mendoza Ibáñez 1999). We will not be exploring it in this article, but we need to distinguish it from the issue of the differentiation of metaphor and metonymy. User-relativity does not necessarily imply that the metaphor and metonymy cannot in general be cleanly differentiated or that, for a given user, particular cases of metaphor and metonymy cannot be cleanly differentiated; 
and, conversely, a lack of a clean differentiation between the notions of metaphor and metonymy does not necessarily imply user-relativity.

Because of its aims, this paper does not rest upon any particular definition of metaphor or metonymy, but instead on other authors' claims for metaphoricity or metonymicity of examples used, or on the present author's judgments of how particular examples would be classified in the field. The paper does nevertheless embody a cognitive assumption, in viewing metaphor and metonymy as being largely to do with cognitive representation and processing issues as opposed to the surface form of utterances. (In the case of lexicalized metaphor or metonymy the representation and processing may have occurred in the past, and thus merely be part of etymological motivation.) To the extent that metaphor and metonymy are matters of processing, the issues in this paper amount to questions such as the extent to which the processing creates or traverses similarity and/or contiguity links between conceptual items.

However, the word "link" will be meant in a very general and theory-neutral way. Links certainly include those between target aspects and source aspects that are proposed in an explicitly mapping-based account such as Conceptual Metaphor Theory, for instance when the participants in a love relationship are linked to occupants of a travelling car. But the notion is broader: for example, even though the sentence My job is a jail is analysed in the classinclusion approach (Glucksberg 2001; Glucksberg and Keysar 1990) in terms of a category of entities that includes both the job and physical jails, we will still describe it as implicitly involving a "link" between the job and either a hypothetical physical jail or the general category or concept of physical jails, even if no direct link is established in the understander's mind or proposed in the theory. This way of talking is just in the service of having a uniform way of describing the fact that, in metaphor, at least one target item is explicitly or implicitly, and directly or highly indirectly, associated with at least one source item. Although the class-inclusion theory's attention is on the idea of class inclusion as such, our attention is on the nature of the implied link between target item and source item, e.g. between the job and the (hypothetical) physical jail, or between the job and the physical-jail category. This link could, for instance, be regarded as a similarity link based on possession of whatever property or set of properties are held to define the superordinate category under which both target item and source item are placed. In the job/jail example, the similarity might consist of both the job and a physical jail being constraining and difficult to escape. (Care is needed here to postulate suitably abstract notions of constraining and escape, in light of the circularity objections raised by Ritchie [2006] and others).

Also, a link can take a collapsed, degenerate form: namely, that of an imaginary identification. For example, if in a blend space (Fauconnier and Turner 1998; Turner and Fauconnier 1995, 2000, 2002) one entity is identified with another, that identification is itself a link in our sense. And if the entities come from input mental spaces, the corresponding entities in those spaces can also be said to be linked indirectly with each other via the identification link 
in the blend space. Finally, to the extent that metaphor and metonymy are in part processing issues, we need to keep in mind the possibility that links might only be classifiable as metonymic or metaphorical by taking into account the way the links are used in processing rather than or as well as any other aspect of their nature.

The structure of the rest of the paper is as follows. In Section 2, we mainly consider whether a distinction between metaphor and metonymy can be found in a distinction between similarity and contiguity. In Section 3 we look at the extent to which source/target links are themselves kept as part of the messages conveyed by metaphorical or metonymic utterances. Section 4 briefly examines two further possible grounds for differentiation, namely the interaction with conceptual compartments such as domains and frames, and the role of imaginary identification/categorization of target items and/or source items. Section 4 also comments further on intermediacy and overlap of metaphor and metonymy, and briefly considers claims that (some) metaphor can be viewed as double metonymy. Section 5 concludes, and explains how can be profitable to analyse utterances at the level of the dimensions of variation discussed in the article (similarity, etc.), as opposed to the higher level of metaphor and metonymy as such.

\section{Similarity versus contiguity?}

A traditional view has been that metaphor is a matter of similarity between source and target items, and metonymy a matter of contiguity between them (Dirven 2002; Feyaerts 2000; Jakobson 2002 [1956]; Lodge 1977; Norrick 1981; Ullman 1962). Haser (2005) provides a review. There is an enduring intuition that in metonymy the source and target item are related in some salient and easily accessed way, making the metaphor of spatial contiguity reasonable. In this sense, a composer is contiguous to his/her music, a time period to an important event occupying it, etc. Contiguity also includes, of course, more physical cases, as of a bottle being contiguous to its contents.

Contiguity is meant to have no whiff of likeness. But many authors have noted the slipperiness of the notions of similarity and contiguity (e.g.: Chiappe 1998; Cooper 1986; Dirven 2002; Haser 2005; Riemer 2002). Norrick (1981: 27) says that "the line between principles of similarity and of contiguity is at times fuzzy" (although he does not go on to explore this fuzziness). The slipperiness of the notions compromises their ability to differentiate metaphor from metonymy.

In addition, metaphor can impose similarity rather than resting entirely on already noticed similarity (Black 1993 [1979]; Haser 2005; Indurkhya 1992). Consider an utterance that metaphorically casts a particular cloud as a camel, such as The camel was high up in the sky. For speaker or hearer, the cloud might initially only have a slight visual similarity to a camel; but the act of using the metaphor causes speaker and/or hearer to view the cloud much more as a camel. The structure of a camel is imposed on the cloud, giving the latter a structure that would not, or could not as easily, have been discerned otherwise, and may be partly artificial. Effects can include the division of a part of the 
cloud into subparts in a non-obvious way, or conversely the agglomeration of two distinct parts of the cloud into one undifferentiated part from the point of view of camel shape. Analogously, viewing a marriage as a business may cause one to add a structure to marriage that one had not previously perceived.

But we will see that similarity and contiguity are not as distinct as is assumed even by previous critics of them as a basis for differentiation. The argument is in two parts. First we argue (in Section 2.1) that there appears to be no bar to viewing metaphorical linkage between source and target in metaphor as a special type of contiguity. Thus, if or when metaphorical linkage amounts to similarity, similarity is a special type of contiguity. Secondly, we argue a partial converse to this (in Sections 2.2 to 2.4): that certain familiar forms of contiguity involve similarity in an essential way, where moreover this similarity can sometimes be akin or even identical to the similarity underlying some metaphor.

The discussion takes contiguity to include not just relations that have specifically been labelled as such but also other relations such as pragmatic functions (Barcelona 2002, 2004; Nunberg 1978). The sets of relations discussed under the heading of contiguity and those under the heading of pragmatic function are very similar. In effect the discussion regards any relationship that has been held to be metonymic as a possible type of contiguity.

Similarity can at one extreme be a matter of sharing some simple features and at the other a matter of a complex structural analogy. We also need to keep in mind a broad distinction in the ways in which things can be similar. A road can be similar to a snake in virtue of the shape of each, and one plan of action can be similar to another in virtue of their structure, similarity of individual steps, etc. These are examples of two things being intrinsically similar similar because of their own natures, independently of relationships to other entities outside themselves. On the other hand, in the context of metaphorically casting an organization as a solar system, the term planets could describe major employees even though there is no (relevant) intrinsic similarity between a planet and an employee. Relative to the overall similarity between the organization and a solar system we can say that employees and planets are extrinsically similar - similar because of their relationships with other things taking part in an overall structural analogy. Of course, two things may be similar because of some mix of intrinsic and extrinsic similarity.

We will not assume that all metaphor is necessarily based on similarity. In particular, some metaphors have been held to be based on experiential correlations between source and target (Barcelona 2000b; Grady 1997; Kövecses 1990; Radden 2002). For example, an experienced correlation between seeing and knowing (in that seeing can lead to knowledge) may be at the root of a metaphorical view of KNOWING AS SEEING. Now, whether this metaphorical view, once created, is a matter of similarity is a contentious matter. For instance, in one such case (SADNESS IS DOWN), Barcelona (2000b) claims that the metaphor involves similarity, but Haser (2005: 44) throws doubt on this. Fortunately, we do not need to adjudicate the matter in this paper. The argument of Section 2.1 actually applies to correlation-based metaphorical links as well as to similarity links; and the arguments of Sections 2.2 to 2.4 are not 
affected in their nature or significance by the presence or otherwise of non-similarity-based metaphor. Hence, the remainder of the paper will refer both to similarity-based and to correlation-based metaphor, but will leave open the possibility that some or all of the latter is also within the former.

One move that might be attempted is simply to disallow similarity from the class of associations called contiguity (Feyaerts 2000, following Ullman 1962). Then, of course, one would get a crisp distinction between (similarity-based) metaphor and metonymy. However, such a move seems unprincipled and to be made just to save the distinction, as opposed to examining the phenomena to see what the useful distinctions are, if any. So, we will assume that the notion of contiguity does not in itself contain a stipulation against similarity.

\subsection{Metaphorical linkage as contiguity}

Basically, we ask why metaphorical links shouldn't themselves be regarded as contiguities. The fact that (at least) similarity links in metaphor are not normally regarded as contiguity links, or the fact that authors uncritically portray similarity and contiguity as being different types of relationship, is hardly a valid answer to the question, as there is no accepted definition of how broad contiguity is. The term "contiguity" is in itself highly metaphorical and susceptible to a wide range of interpretations, as has often been observed. It is thus perhaps surprising that the question of metaphorical linkage counting as contiguity has not been raised more often.

Consider the widespread phenomenon of referential metaphor. Typically, referential metaphor is said to occur when a definite noun phrase is used metaphorically to refer to some target item, as in (1), from Gibbs (1990):

\section{(1) The creampuff didn't even show up.}

A boxer in the context is being metaphorically viewed as a creampuff and is being referred to by the phrase The creampuff. Another, more mundane and conventional, example would be They have reached the third milestone on the project using the phrase the milestone to refer metaphorically to an important, planned event in the project. Thus, assuming that underlying (1) there is some postulated similarity link between the boxer in question and a hypothetical creampuff (in the literal sense), we can use this link to achieve indirect reference to the boxer (target item) via direct reference to the creampuff (source item), just as we can use an alleged contiguity link in a metonymy to achieve indirect reference to a target item via a direct reference to a source item.

Referential metaphor can also use correlation-based metaphorical schemata. Consider the passage: Susan sank into a pit of sadness. She stayed at the bottom for many months. Let us assume for the sake of argument that the passage is to be analysed using the SADNESS IS DOWN metaphor and that this is correlation based. Then in the second sentence the phrase the bottom is a referential metaphor for the worst phase of her sadness state. 
So, is there anything about metaphorical links that should prevent us from regarding them as a special case of contiguity links, at least when they are being used in referential metaphor? One sharpened version of this question could be: If contiguity links in general are salient semantic or pragmatic associations or salient applications of pragmatic functions, is there anything about similarity or correlation-based links in referential metaphor that should prevent them from qualifying as contiguities along with other types of salient association/function?

Before going on we should dispose of one alternative to an assumption made a moment ago: the assumption that the phrase The creampuff in (1) refers to a hypothetical literal creampuff. One might argue instead that while creampuff in the noun phrase does refer to the category of literal creampuffs, there is no act of postulating a member of that category: rather, the noun phrase acts much as if it had been The person who is, metaphorically speaking, a creampuff using a creampuff purely predicatively. (This would be consistent with a class-inclusion account of metaphor.). However, we can still say that there is an (alleged) similarity between the boxer and (literal) creampuffs in general, or a similarity relationship between our concept of the particular boxer and the general concept of (literal) creampuffs. Our question would then become: Is there anything about this similarity that disqualifies it from being a type of contiguity? For simplicity, in the following we will stick to the assumption that the phrase The creampuff in (1) does refer to a hypothetical literal creampuff, on the understanding that the discussion could be adjusted to fit category-based accounts.

Another distinction to note before going on is that the issue of whether correlation-based metaphorical links can be regarded as contiguities is different from the issue of whether the original correlations themselves are so regarded. If Susan's state of sadness does not in fact cause any physical downness (e.g., drooping body), but is metaphorically cast as an imaginary physical downness, then the fact that some sadness states can cause, and therefore be contiguous to, downness does not force us to consider Susan's sadness and the imaginary downness to be contiguous. However, it is certainly possible to allow the notion of contiguity to encompass potential as opposed to actual causation, in which case the metaphorical link would be one of contiguity, whatever else it might be. However, we do not rely on this argument in the following.

Some grounds could be imagined for trying to maintain that metaphorical links, whether similarity-based or correlation-based, should not qualify as contiguity links. We will treat these in turn and argue against them. Naturally, there may be grounds beyond those considered here.

First, it might be claimed that metaphorical links are more a matter of (possibly culture-wide) mental imposition upon the world than are the contiguity links in generally recognized forms of metonymy. Or, to paraphrase, perhaps metaphorical links are much more in the mind whereas metonymic links are much more a case of reflecting what is objectively in the world. Thinking of a love relationship as a physical container is arguably more an imposed, mental 
view than regarding a physical container as being related to its physical contents. ${ }^{1}$ However, it is difficult to sustain a rigid contrast in general. As Dirven (2002) says, contiguity is itself to some extent partly in the eye of the beholder, and Norrick (1981) takes a similar view. It is partly a mentally, socially and culturally constituted matter that, for instance, a particular group of people is the football team representing Finland, and yet the word Finland can metonymically refer to the group, as in Finland lost the match. The situation is similar for many other types of metonymy where the source item plays some sort of social or political role with respect to the target item or vice versa, as in Bush attacked Iraq with Bush as source item and the USA or the US military as actual attacker. The Representational metonymies to be discussed in Section 2.2 - where, say, a pictorial image in a painting is used to refer to the depicted object, or vice versa - involve a mentally imposed representational link; also, Goodman (1968) argues that there are conventional and stipulative aspects to the way that paintings, etc. do their representing. Finally, in the celebrated example of using the phrase The ham sandwich to refer to the restaurant customer who ordered the sandwich (Nunberg 1995), the act of ordering something in a restaurant only makes sense given a suitably constituted socioeconomic culture, one where certain discourse acts are regarded as constituting ordering.

Furthermore, we can argue that many metaphorical similarity relationships do exist in the world, or arise objectively from it, just as much as many metonymic relationships do. This is clearest when the metaphor rests on a complex structural analogy such as that between an army and a society of army ants (example from Goatly [1997: 163]) or that between a commercial company and a solar system. There is a sense in which the partial isomorphism of structure really exists. It is a mathematical aspect of the world that exists just as much as a simple, familiar mathematical object such as the number 9 does. And, the partial isomorphisms exist just as much as the link between, say, the date 11th September 2001 and certain terrorist events does. So, given that dates and events are used metonymically for each other - e.g. the (abbreviated, US-style) date $9 / 11$ for some terrorist events — and given that their relationship is a contiguity, it seems artificial not to regard the abovementioned analogical links as contiguities.

Secondly, perhaps contiguity and metaphorical linkage could be distinguished on grounds of structural correspondence. (Barcelona [2004] provisionally suggests this.) Perhaps similarity in metaphor involves a correspondence of some structure between source and target whereas contiguity does not: contiguity just relates two wholes that it leaves unanalysed - so that their intrinsic similarity or otherwise is not an issue - and whose relationships to other things are irrelevant - so that extrinsic similarity is not an issue either. Now, similarity-based metaphor can indeed be seen to involve at least some small amount of structural correspondence. Even when the similarity consists only of the source and target items having one corresponding feature, such as perhaps some sort of weakness in the boxer/creampuff case, we can see a structural correspondence: the boxer corresponds to the creampuff, the weakness on the target side corresponds to the weakness on the source side, and the boxer having the former weakness property corresponds to the creampuff having the latter weakness property. But, the trouble is that some metonymy involves structural corre- 
spondence as well, as we will see in Sections 2.2 and 2.4, where the structural correspondence is at least as rich as the minimal sort found in the boxer/creampuff example of metaphor.

As for correlation-based metaphor, if this does not (always) involve structural correspondence, then, given that metonymy does not usually involve structural correspondence, structural correspondence cannot be used as a metaphor/metonymy differentiator. If on the other hand (some) correlation-based metaphor does involve some structural correspondence, as claimed by Barcelona (2000b), then we are back to the point that so does some metonymy.

Thirdly, perhaps contiguity links should be restricted to associations that are conventional or firmly established (cf. discussion in Haser [2005: 22]). But even if this is correct it will not work to provide a distinction with similarity in metaphor, because most similarity in metaphor is highly conventional or firmly established, and the metaphorical links of correlation-based metaphor are also firmly established.

Finally, it might be claimed that in metaphorical similarity there is no real source-side entity corresponding to the target-side entities, whereas in metonymy there is. For example, metaphorically casting a person Richard as a lion does not involve a particular, real lion, whereas metonymically referring to some real artworks via an artist does involve the artist being real as well. However, some core types of metonymy are open to having merely hypothetical source items. In a conversation in a library about the location of books about certain topics, we can say Santa Claus is on the topic shelf meaning that books about Santa Claus are there, just as we can say Alexander the Great is on the top shelf or Car engines are on the top shelf with analogous intent. Equally, we can say Santa Claus is in the left-hand part of the picture, with Santa Claus being a case a Representational metonymy (Section 2.2). We can also similarly say Lions are on the top shelf and There's a lion in the left-hand part of the picture without assuming that any particular real lion is discussed or depicted. Conversely, a metaphor source item can be real, as in Singapore is the Britain of the Far East (example quoted by Wee [2006] and following a common pattern of using a well-known existing entity as a metaphor for another entity).

The conclusion so far is that there is nothing to stop us regarding the metaphorical links traversed in (at least) referential metaphor as special cases of contiguity. However, our claim is not restricted to referential metaphor as normally conceived, i.e. as being about metaphorically-used definite noun phrases, any more than metonymy is confined to definite noun phrases. Rather, whenever a metaphorical link is used for accessing something in the target via something in the source, irrespective of the surface linguistic forms involved, we can claim the link is being used as a type of contiguity just as much as we can in standard referential metaphor examples such as (1). For one thing, our discussion would not be essentially chaged if (1) had used an indefinite noun phrase, as in Some creampuffs didn't even show up. More distantly, consider the common use of the phrasal verb eat up to refer to commercial taking-over, as in a sentence of form Company A tried to eat up Company B. We can say that there is a hypothetical act of physical 
eating-up that is conceptually contiguous to the real taking-over, just as much as we can say that in the case of (1) there is a hypothetical creampuff that is conceptually contiguous to the real boxer.

\subsection{Contiguity involving similarity, 1: representational metonymy}

In this subsection and the next (2.3) we will be arguing that two (salient) types of contiguity can be viewed as involving similarity. This point is a partial converse to that of the previous subsection (2.1).

Representations (things that represent) and their representatees (the things they represent) are often used to stand for each other in metonymy. Thus we have REPRESENTATEE FOR REPRESENTATION and REPRESENTATION FOR REPRESENTATEE. These are both covered by Warren (2006), but with different names from ours. We will use the term Representational metonymy to cover both directions of the metonymy. Warren's examples of REPRESENTATEE FOR REPRESENTATION include Ari painted a tanker (quoted by Warren from Fass [1997]; a tanker is the metonymic source phrase). Let us assume that in context the sentence means that Ari painted a picture of a tanker, or a picture of various things including a tanker. Here the source REPRESENTATEE is the (possibly imaginary) tanker and the target REPRESENTATION is either the picture as a whole or the image of the tanker in the picture. Other examples would be There's a tanker in the left hand side of the picture and Tony Blair is on the left hand side of the photo, both of which make it more explicit that a physical representation is being indirectly referred to (by the phrases a tanker and Tony Blair respectively).

But the REPRESENTATION need not be a visual representation of the REPRESENTATEE. For instance, it can be an acoustic representation, as in “... Knecht's symphony begins amid beautiful countryside, but, rather more rapidly than in [Beethoven's Pastoral Symphony], a storm approaches, breaks and fades away ...” [emphasis added]. ${ }^{2}$ It is clear from the surrounding text that what is under discussion is an acoustic image of a represented storm. (This is worth noting because the above quotation, taken by itself, bears a possible contrasting, interpretation in which storm is a metaphorical description of non-representational musical events in the symphony.) And the REPRESENTATION in a Representational metonymy need not be any type of perceptual representation, as it could be an idea in someone's mind and could concern something non-perceptual, as in Sally's disappointment was at the back of John's mind all day long. Here the phrase Sally's disappointment metonymically refers to some IDEA OF Sally's disappointment (which is itself being metaphorically viewed as a physical object in John's mind, which is metaphorically viewed as a container).

An example of the reverse metonymic pattern, REPRESENTATION FOR REPRESENTATEE, is: In Goldfinger Sean Connery saves the world from a nuclear disaster (Warren 2006: 48), with actor Sean Connery himself or the 
moving images of him in the film as the REPRESENTATION and character James Bond as the REPRESENTATEE. It is of course the (fictional) person James Bond who saves the (fictional) world.

Now, it is certainly true that even when the REPRESENTATION is a visual item or physical object (e.g., an image or an actor) and the REPRESENTATEE is a physical object, the REPRESENTATION need not bear any significant visual resemblance to the representatee. In the sentence The town is on the left hand side of the map the visual representation of the town could be just a small black dot, and thus have little resemblance to the actual appearance of the town. However, we are concerned henceforth with the prominent special case of Representational metonymies where the representation is indeed based, at least in part, on some substantial sort of intrinsic perceptual similarity, and will take the visual-similarity subcase of Representational metonymy as particularly salient. In situations involving photos, pictures and the like the representation relationship is normally based at least in part on visual similarity, though other factors such as convention and stipulation can also be present (cf. Goodman 1968). Naturally, the visual similarity often involves a high degree of structural correspondence.

Clearly, if we are to claim that metonymic links in general are contiguities, then we must admit that in similaritybased Representational metonymies the contiguity between source and target happens to take the form (at least in part) of similarity. Moreover, the similarity is central to the metonymy, not some incidental feature of it. These obvious points have not been given due weight in discussions of the metaphor-metonymy distinction. Perhaps this is because examples of Representational metonymy are rare in the metonymy literature, according to Warren (2006). This investigative rarity, however, does not do justice to the prevalence and ordinariness of the phenomenon.

Warren (2006: 49) herself seeks to distinguish the type of similarity involved in similarity-based Representational metonymies from the type of resemblance involved in metaphor. She says that the former simply involves "matching" the REPRESENTATION with the REPRESENTATEE whereas in ("many") metaphors the resemblance involves property selection and adaptation. These claims of Warren's are disputable. First, she does not explain what this "matching" in the metonymic case amounts to. Secondly, the visual similarity in the metonymic case will almost always involve significant property selection (except in the most photographic of depictions) and often some measure of adaptation (e.g., colours may be intensified, shapes simplified). Thirdly, she only says "many" metaphors. Fourthly, other authors have regarded the resemblance relation that visual depictions have to what they depict as usable in metaphor: for example, such resemblance is an example of one of Norrick's (1981) iconic semiotic principles, and this general semiotic principle induces a metaphoric principle in the special case of language. ${ }^{3}$ Finally, it is difficult to see any fundamental difference between the types of visual resemblance possible in the metonymies and those possible in image-based metaphors (Lakoff 1993; Lakoff and Turner 1989). In image-based metaphors — also sometimes called resemblance metaphors, though this is too vague a term - two physical objects or images are put into a metaphori- 
cal relationship on the basis of their visual appearance (which can include motion), examples being the road snaked through the desert, where the word snaked uses an image metaphor to describe the shape of the road, and The rock that saved him was lathered and fringed with leaping strings of foam (quoted by [Goatly 1997: 271]) where the word lathered uses an image metaphor to describe the foamy rock and the words leaping and strings set up further image metaphors to describe the foam itself.

It could be argued (and perhaps this is Warren's point) that in image metaphor one needs to understand just how the two things are similar in order to understand the utterance, whereas in Representational metonymy one can simply take it on trust that there is a similarity or some other sort of representational connection. The claim would be that to understand, say, what it is for a road to snake we need to think about what a moving snake looks like; whereas to understand There's a snake in the left hand side of the picture we only need to know that there is some subimage or other in the picture that is intended to depict a snake. However, this difference is at most a matter of degree and particular circumstances, and does not support any sharp distinction between Representational metonymy and imagebased metaphor. In the case of Tony Blair is on the left hand side of the photo, could we be said to have properly understood the utterance without understanding something about how a representation in a photo could be similar to Tony Blair's actual appearance, so that the understanding involves more than just realizing that some similarity exists? Conversely, in the case of The road snaked through the desert we do not, for most purposes, need to have more than a vague idea of the bendiness of the road. It is not clear that the visual similarity considered by the understander is more detailed than the visual similarity the understander needs to consider in the Blair photo case.

In response one might claim that in the Blair photo case, the act of metonymy as such is a very bare one, consisting simply in assuming that there is some visual representation of Blair in the photo, and does not require knowledge of what Blair looks like; but understanders perform an additional, pragmatic inference that that representation is probably a shape that looks like Blair, and if they happen to know what Blair looks like they can flesh this looks-like relationship out. However, we could counter this with the parallel claim that in a sentence like The road snaked across the desert, the act of metaphorical understanding is a very bare one, consisting simply in assuming that there is some visual similarity between the road and a snake, and does not require knowledge of what a snake looks like; and there is an additional pragmatic inference that that similarity is probably one of physical shape, and if understanders happen to know what a snake and its movements look like they can enrich the similarity. Ultimately, the point is that in both Representational metonymy and image-based metaphor we have a relationship of similarity; the degree to which that similarity is apprehended by the understander is a matter of how rich an understanding the understander comes to, irrespective of whether we have a case of metonymy or a case of metaphor.

Also, note that even if a town is represented by merely a small dot on a map, so that there is little or no intrinsic 
similarity, the spatial relationships within the map itself between the dot and other representations will be structurally analogous to the spatial relationships of the town to the representatees of those other representations. Thus, just as in metaphor, it is often the external associations of source and target items, rather than their internal structure, that are important in source/target similarity, so that the similarity is largely extrinsic to any given source/target link. In Representational metonymy the external associations are often an implicit part of the representational relationship between a particular REPRESENTATION and a particular REPRESENTATEE. Analysed in this way the map could be said to be a metaphorical representation of the geographical region in question, and the metaphorical links between town-denoting dots on the map to real towns are similarity links used as contiguities, on the lines of Section 2.1. It is just that we are now arguing that something we started off assuming was a contiguity link is also a similarity link like those used in a type of metaphor, rather than arguing as we did in Section 2.1 that a similarity link in general can also be used as a contiguity link.

It is not just that it is difficult to put a wedge between the general nature of similarity in Representational metonymy and that of similarity in image-based metaphor. Rather, we can even argue that the just the same particular similarity can operate in both metonymy and metaphor. On the metonymy side, consider the following, where the label " $2 \mathrm{my}$ " is short for "metonymy case of 2 "

(2my) There's a snake on the left-hand side of the drawing.

referring to a wavy line in the drawing that is intended to depict a snake. On the metaphor side, consider the following, where "2or" is short for "metaphor case of 2"

(2or) There's a snake on the left-hand side of the drawing.

as a way simply of describing a line in a drawing, where the line is not intended to depict a snake (it might depict something unconnected with snakes). (2my) and (2or) are deliberately the same sentence, but involved in different utterance events and we use different labels for ease of reference.

Suppose the snake lines in the two drawings are identical. Then both examples involve exactly the same type and degree of visual snake/line similarity, and it is likely that there is no other type of similarity in play (such as would arise if, say, in one of the examples the line were drawn in ink containing snake bile!). This raises the possibility that we should classify at least some Representational metonymy that relies on similarity as also simultaneously being metaphor.

But we should also wonder whether the contiguity in Representational metonymy is more than just the similarity. We might argue that in Representational metonymy we also have the extra feature that the similarity is being used in a 
particular way, namely in an act of representation, whereas metaphorical source items do not represent corresponding target items. But there is a case for suggesting that metaphor itself does involve a representation relationship: that source-domain items in metaphor do represent corresponding target-domain items, in the mind of someone using the metaphor. For example, in (2or) an imagined snake could be said to represent the line. Or, the person's idea of a snake could be said to represent the line (in the special source-to-target sense envisaged, as well as representing a snake in the ordinary way). It all depends on one what one means by the word "representation."

Whatever the relative merits of these arguments as to whether Representational metonymy has a feature beyond similarity that metaphor does not have, the point holds that a difference between metaphor and metonymy cannot solely be based on metaphorical and metonymic links always differing as to whether similarity is involved or even on what forms of similarity they involve.

\subsection{Contiguity involving similarity, 2: partitive metonymy}

We now turn to a very different type of contiguity, namely the contiguity involved in WHOLE FOR PART and PART FOR WHOLE metonymy. We will use the term Partitive contiguity or metonymy to cover both directions. We will see another important way in which contiguity can involve similarity. Similarity will be highly relevant to the way that some Partitive metonymy works, and in these cases we will say that the PART and WHOLE are relevantly Partitively similar or that the PART is relevantly whole-similar for short.

Relevant Partitive similarity arises when the WHOLE and the PART to some extent share particular features that are important in the motivation for the metonymy. This applies, for example, in the traditional metonymic use of hand to mean a sailor. Important (traditional) functions of sailors, such as grasping a rope, are performed partly by their hands. So, there is a sense in which a sailor and his/her hands are functionally similar to some degree (of course, what the hands do in grasping is only part of what the whole body does in grasping). It is precisely this partial function sharing - hence, partial functional similarity — that motivates the metonymy. But we can go further: to a degree, the whole person has the function in question because of having a part that has that function or an approximation to it. The parthood is central to the similarity, and the similarity is central to the significance (in context) of the parthood.

We are not concluding that, because some sort of similarity is involved, metaphor is therefore involved. This would prejudge the question of whether metaphor restricts the type of similarity, or involves more than just similarity. However, it is worth mentioning here the "like" test for distinguishing whether two items A and B have a metonymic or metaphorical relationship (Gibbs 1999). The core intent of the test is presumably to test for (metaphor-supporting) similarity. According to the test, if saying $A$ is like $B$ is appropriate in the context then we have a case of metaphor. But it might be thought odd to say that Sailors are like their hands or The hands are like the sailor, even in a context where 
sailors' use of their hands is salient. However, if anything this shows the dubious validity of the test for our current purposes. The conditions under which we might judge any given form of words like Sailors are like their hands to be appropriate will be affected by many factors. Also, the test is unfair in using an impoverished likeness sentence: we should really be assessing a sentence like Sailors are like their hands in that they have functions such as that of grasping rope in common. Surely this sentence is appropriate and true in the relevant context. In short, the suspicion is that the test picks up on, if anything, just default preconceptions of likeness rather than the more specialized, less obvious but nevertheless relevant and technically important forms arising in specific contexts.

We will look at further examples of relevant Partitive similarity. The shared features in the examples happen to be ones of function or appearance, but the phenomenon could apply much more widely. The central observation about our examples will be that matters of appearance or function will be what the utterance is getting at, and the PART will be similar to the WHOLE precisely in appearance or function respectively. We will also continue to see in the examples that the WHOLE has the appearance or function it has partly because the PART has it, so the similarity arises in part from the parthood; and (in the PART FOR WHOLE direction) the particular part is chosen in the metonymy because of the similarity.

It is common for one important contribution, or even the main contribution, to the appearance of something to come from a certain type of part of the thing, notably the outer surface of the whole thing, or the outer surface of an especially salient part of the thing. Warren (2006: 42) mentions the metonymic PART-FOR-WHOLE use of the word palefaces by Native Americans (at one time) to refer to white people. So consider a sentence such as We run away when we see palefaces, uttered perhaps in a 1950s cowboy film. The person's face is relevantly similar, in appearance, to the person as a whole (or more precisely to their skin as a whole): you can normally tell someone is a white person by looking just at their face, and the fact that someone is white is highly relevant to the understanding of the sentence. Also, the very motivation for the particular type of metonymy in question is precisely the similarity of appearance of face to whole skin and then to the whole person.

Consider now the following example (mentioned by Warren [2006: 43], but of course an example of a common way of speaking):

\section{(3) Everyone who wants a roof should have one.}

Although the phrase the roof could be referring literally just to roofs, it is more likely to be metonymically referring to roofed dwellings. Part of the function of a dwelling is to shelter the occupants, and an important aspect of that function is provided by the roof. Assuming the sheltering function is relevant to the understanding of the sentence in context, we see that roofs and dwellings are relevantly Partitively similar. 
The above examples are about parthood within physical objects, but relevant Partitive similarity is not confined to these. A more abstract example is The meal was enjoyable when the phrase the meal refers not just to the food served and the eating of it but the whole occasion, including conversation, etc. (This metonymy is similar in style to the metonymy that Norrick (1981: 93-94) discusses of [to] cook referring to the whole meal-preparation process.) The meal in the narrow sense is a PART of the whole occasion. They share the function of providing food to the eaters; the occasion has that function because (in part) the narrow meal does so; and the narrow meal is by default an important aspect of the enjoyability.

The hand (for sailor), palefaces, roof, and meal examples are all PART-FOR-WHOLE, but the point works for WHOLE-FOR-PART as well. Consider the sentence She has a good head (Warren 2006: 44). Warren mentions an interpretation in which the head links metonymically to the person's intelligence viewed as a PART of the head. Clearly, the head's function of engaging in intelligent thought comes directly from the PART in this analysis. Some researchers might object that what is happening in WHOLE FOR PART cases is merely zone activation rather than metonymy - see, e.g., Croft and Cruse (2004), following Langacker, and Paradis (2004). There is no room to argue against this stance here, but we do not need to rely on the WHOLE FOR PART direction anyway: the above consideration of PART FOR WHOLE is enough for our purposes.

The similarity in Partitive metonymy can be like that used in some metaphor. It is difficult to drive a wedge between appearance-based relevant Partitive similarity and appearance-based similarity in image-based metaphor. As regards function-based relevant Partitive similarity, note that functional similarity is key in some metaphors, as in brain-as-computer or vice versa, insofar as both entities are viewed as having problem-solving as one function.

Finally, we return to the issue addressed in Section 2.1 of whether metaphor and metonymy can be clearly divided as regards the degree of subjectivity and mental imposition. While it is plausible that metaphor generally has these qualities to a higher degree, it is by no means clear that the difference across the board is enough for a clear differentiation. In particular, parthood can be subjective and mentally imposed, especially when the entities are at least somewhat abstract. For instance, in the meal/occasion case, the dividing line between the whole occasion and the meal as a sub-occasion of eating is fuzzy and subjective. Are drinks included within the (narrow) meal? Are snacks, coffee etc. away from the main table included within it? Also, food might be available buffet-style on a table for guests to get and take to other positions whenever they want, so that there are no spatial or temporal boundaries to the narrow meal at all, and yet it is still appropriate to use the word meal to refer metonymically to the whole occasion (and the whole occasion is still more than just a narrow meal aspect). In such case the very idea that the occasion has a part constituting a narrow meal is a mental imposition of structure, quite aside from the question of what the exact boundaries of that part are. 


\subsection{Contiguity involving similarity, 3: other cases}

Other types of metonymy may involve similarity in an essential way. Panther (2006) discusses phrases like $a$ Pearl Harbour where a proper name is used as if it were a common noun. He analyses this particular example as involving, first, a metonymic step to an event, and then a metonymic step from that specific event to other events of the same kind. Panther (2006: 181 at note 24) says that this second metonymic step goes from the specific event to events that are, as he says, "like" the original one "in significant respects." Thus, the essential nature of the metonymic step is to traverse a similarity link.

There is even some appreciable similarity in the case of a sports team or a single athlete representing a country. Such representation only makes sense in the context of more than one country (or other social, political or geographical unit) being represented. So, there is a one-to-one correspondence between some countries and their athletes/teams. This can by itself be viewed as a minimal type of structural correspondence (hence similarity) - minimal in the sense that correspondence of relationships is not yet involved. But we can enrich the correspondence by taking competitive relationships between teams/athletes to correspond to competitive relationships between countries. The structural correspondence is extrinsic to any one country and its team/athlete, but this is not a problem as the similarity in metaphor generally can also be extrinsic relative to individual items involved (cf. the solar-system/organization similarity in the preface of Section 2).

In addition, in the case of a team as opposed to a single athlete, there is additional intrinsic similarity that conceivably contributes to the metonymy. The team is similar to the country in being composed of people who work cooperatively for the good of the team (and hence also for the country), just as the people in a country work cooperatively in some measure for the good of the country. Part of the very reason the team is viewed as representing the country may be that it has the features just mentioned, though this deserves further discussion.

\section{Source/target links as part of the message (link survival)}

Warren $(1999,2002,2006)$ asserted versions of the claim that, in a metonymy, the source/target link itself is kept as part of the message of the utterance. Similar or strongly related views have also been expressed by Croft (2006), Dirven (2002), Haser (2005), Panther (2006) and Radden and Kövecses (1999). As an example of the phenomenon, when people understand the sentence Finland lost the [football] match they surely construct semantic mental representations in which the football team in question is indeed identified as being the team associated with the country Finland; the mental identification of the team is not (or at least not solely) done by some other means. Thus, the metonymic link between Finland and the team is preserved as part of the representation of sentence meaning: the role that the target 
item plays in relation to the source item is an important part of the message, not just a processing route to determining the message. The Finland-to-team link is not (just) used to determine a mental list of player names, say.

On the other hand, inclusion of links within the message supposedly does not happen in metaphor. Dirven (2002) claims this, in effect; and Warren (2006: 15) even says that metaphor involves the "annihilation" of the source by the target. Consider the sentence They have reached the third milestone on the project. Even if understanding of this is obtained on-line by considering a hypothetical physical milestone or the physical-milestone category, it is reasonable to suppose that there is no need to have, within the resulting representation for the figurative meaning of the sentence, a record of the fact that the plan component in question is linked to that hypothetical milestone or milestone category.

The claim that, in metonymy, the source-target link (at least often) survives into sentence meaning is appealing. Indeed, in many cases of metonymy there is no way of specifying the target item other than by reference to the source. Someone can utter or understand Finland lost the match without having any knowledge of the player's names, or any way of referring mentally to the team other than by some analogue of the description the football team of Finland. And even when there is some other readily available way of mentally referring to the target, part of the point of the sentence would often be lost if the explicit link to the source were thrown away. However, it remains to be seen how universally the source-target link needs to survive. For instance, consider the sentence John has brains where brains are being used metonymically to refer to intelligence (cf. Haser 2005: 46). As Haser indicates, it is perfectly adequate for the mental representation of the meaning to state simply that John has intelligence, with no reference to brains.

And, on the other hand, we now argue that many uses of metaphor do appear to keep links to source items. (See also Croft [2006], and the notion of knowledge by metaphorical character in Stern [2000].) Part of the point of a poetic or other literary work is often the way in which information is expressed, and in particular the metaphors used. For example, in Shakespeare's play As You Like It the character Jaques says "All the world's a stage ..." and then lengthily elaborates this idea. Part of the message is the comparison of world to theatre (especially in view of the dramatic irony that Jaques's real world is already theatre for us), not just the information about the world in itself that we may get as a result of comparing world to theatre, and then forgetting about the link to the theatre.

More mundanely, many names for things have a metaphorical quality, and it is plausible that use of the names involves remembering the links to source items. An example is the name army ant. The reason army ants are so-called is a rich behavioral similarity to soldiers and other army units (see the popular science exposition quoted by [Goatly 1997: 163]), and at least in case of someone first learning about them it is difficult to believe that reference back to the behavior of real army units is not active in the person's mind as an important part of the conception of the ants.

Again, consider someone using the phrase the camel to refer to a cloud that looks like a camel, and saying The 
camel has broken its neck to describe the cloud coming apart at the place of its so-called neck. Now, Indurkhya (1992) uses the case of a similarity between a camel and a cloud as an example of how structure from a metaphor source (the camel) can be imposed on a target (the cloud), rather than residing intrinsically in the target. (See comments above, in the preface of Section 2.) Thus, the identification of some part of the cloud as corresponding to the neck may be ineliminably dependent on the comparison to the camel, and indeed the head and the rest of the body may only be vaguely related to the subshapes in the cloud, so that we cannot necessarily just regard the neck part as the place where the head part joins the rest-of-body part, because those parts may not themselves be clearly specified. Under these conditions, consider what the understander's representation of the sequence of events has been. How is the place of the breakage to be internally represented? We have to assume either that (a) he/she has kept a detailed, entirely spatial representation of the original cloud, and, after somehow picking out a subregion $\mathrm{N}$ of it as the referent of its neck by considering the shape of camels, remembers only the spatial characterization of $\mathrm{N}$ as the internal representation of where the breakage was, or that (b) he/she refers mentally (whether consciously or not) to the supposed neck part by some representation that could be glossed as "the cloud part, whatever it is, corresponding to the camel's neck" or "the cloud part between the head part and the body part," (perhaps together with a representation of roughly where that part is).

Consider also: There's a camel in the sky, with the word "There's" interpreted existentially (as opposed to deictically), and in a context where it is clear that a cloud is being mentioned. Especially if the understander is not looking at the sky, there is now no specific cloud to compare to a camel, so unless the understander arbitrarily imagines a particular cloud shape, the most natural suggestion is that he/she mentally describes the cloud as having a shape similar to that of a camel.

This point transfers directly to metaphor example (2or) in Section 2.2 in a context where the understander has not seen the drawing and so has no specific line shape to describe unless he/she mentally invents one. Thus, the link is likely to survive into the message of (2or) under certain conditions. Equally, the mental representation of the shape alluded to by metonymy example (2my) is presumably something like "a shape representing a snake." So, for both (2my) and (2or), having links as part of the message is potentially equally important, depending on discourse context.

Although the cloud/camel example and line/snake example (2or) are cases of image-based metaphor, the point they make is not specific to such metaphor. In particular, in any metaphor where source structure is imposed on the target, aspects of the target may best be mentally identified via corresponding aspects of the source. By contrast, there is no particular reason to insist that, with unreflective use of unremarkable metaphorical phraseology such as milestones in everyday discourse, we should take source/target links (if used during understanding) to be part of the message. 


\section{Additional Discussion}

\subsection{Two other possible differences between metaphor and metonymy}

We consider first the idea that a metonymic step stays within a single conceptual compartment of some sort (a domain, Idealized Cognitive Model, frame, etc.) whereas metaphor crosses between different compartments. We concentrate here on compartmentalizations that are static in the sense of not relying on decisions made about the interpretation of the very utterances under consideration, so that when A and B are alluded to in an utterance, the question of whether $\mathrm{A}$ and $\mathrm{B}$ are in the same compartment or not cannot be varied by the utterance itself.

The idea of using a static compartmentalization to distinguish metonymy and metaphor has major problems. For instance, a country can not only be used metonymically to stand for its team, but a country and a football team (even its own actual team) can be put into metaphorical relationship to each other, either way round. The captain can be likened to a national leader, other roles within the team can be likened to roles within society, manipulations of the ball can be likened to interactions within society, etc. Either a country and its team are in the same compartment or they are not, and, in either case, either metaphor or metonymy can link the country and team in an utterance. The particular utterance is not allowed to help define whether the country and team are in the same compartment or not. Utterances (2my) and (2or) supply another example, especially if we assume that in each situation the same line is present, and in each situation the snake is the same imagined, prototypical snake. Utterance (2my) is metonymic and (2or) is metaphorical, but they involve exactly the same interaction with any static compartmentalization. Even if different lines and imagined snakes were allowed in the two situations it would be difficult to find a principled way in which the line and snake could be in the same compartment for (2my) and different compartments for (2or).

A variety of other authors have found problems with compartment-based differentiations between metaphor and metonymy, including Barcelona (2002), Cameron (1999a), Croft (2002), Feyaerts (2000), Haser (2005), Kittay (1989), Moore (2006), Panther (2006) and Peirsman and Geeraerts (2006). However, some authors criticize one proposed compartment-based distinction only to introduce a proposal that itself has flaws. As just one example, Moore (2006) claims that metonymy operates within a "frame" whereas metaphor crosses between frames. He says that the days of the week form a frame. But days can be used metaphorically for each other, as in the following part of a blog posting, created on a Monday: Sunday felt like Monday, so in honor of it [i.e., today] being honorary Tuesday, I am doing two minis [mini-blogs] today... ${ }^{4}$

Of course, if one were allowed to propose a compartmentalization that depended on decisions about metonymy and metaphoricity of utterances - e.g., one put a snake and a line in the same compartment because of a metonymic utterance like (2my) - then the compartmentalization would not be of much use in defining the difference between 
metaphor and metonymy. But one general problem even about static compartmentalizations is that rarely if ever is any clear constraint placed in what one is allowed to propose as being packaged into a compartment, so that for any particular set of examples one can often suggest a static compartmentalization that makes the postulated metaphorical links cross between compartments and the postulated metonymic links not do so. Haser (2005: Ch. 2) makes similar points.

We now turn to another possible ground for differentiating metaphor and metonymy, namely imaginary identification or categorization. As a feature of metaphor this has appeared in various forms and under a variety of names, for example in blending theory (Fauconnier and Turner 1998; Turner and Fauconnier 1995, 2000, 2002) — in that corresponding target and source items become identified as a single item in a metaphorical blend - and somewhat similarly in the ATT-Meta approach (Barnden 2001, 2006; Barnden et al. 2004). It has also been suggested by Warren (2002). The idea is that in the course of understanding a metaphorical utterance the understander imagines that the target item and source item are the same thing (e.g., imagines Richard to be a specific hypothetical lion) or imagines the target item to be in the source item when this is construed as a category (e.g., imagines Richard to be in the physical lion category).

But not only does imaginary identification or categorization fail to be a generally accepted tenet about metaphor, but it is possible to construe metonymy as involving it too. Turner and Fauconnier $(2000,2002)$ and Fauconnier (2009) apply imaginary identification to some metonymically linked items, as well as to metaphorically linked ones: for example, in Turner and Fauconnier $(2000,2002)$ a printing press and a newspaper company that are metonymically related to each other become one item in a blend. Fauconnier (2009) reaffirms the point from Turner and Fauconnier (2002) that in their blending treatment of anger as heat, the heat, the anger and the bodily reactions correlated with anger - and thereby metonymically related to anger - become identified as one element in the blend. Thus, even if imaginary identification were established as essential in metaphor it would not uncontroversially distinguish it from metonymy.

\subsection{Overlap, intermediacy, and combinations of differences}

Our arguments do not prevent some combination of the discussed dimensions, rather than some single dimension, from serving to distinguish metaphor and metonymy. But it is going to be very difficult to come up with such a combination. The snake/line examples (2my) and (2or) from Section 2.2 are similarly if not identically situated on the dimensions of (a) compartmentalization, (b) similarity, (c) contiguity, (d) structural correspondence, (e) link survival, and (f) sourceitem hypotheticality. As for (a): the two examples interact identically with any static compartmentalization, under the assumptions of Section 4.1. As for (b) and (c), in metaphorical (2or) the link is not only a similarity link but can be 
regarded as a metonymically-used contiguity link on the lines of Section 2.1. The contiguity, while different from that in (2my), is similar to it in many respects, e.g. the extent to which it is mentally imposed. For (d): both examples involve the same type and degree of visual similarity, and therefore of structural correspondence. For (e): link survival into the message may need to happen just as much for metaphorical (2or) as for metonymic (2my), as we saw at the end of Section 3. For (f): example (2or) involves a hypothetical snake and (2my) may well do so. It is possible also that the question of imaginary identification/categorization would not distinguish (2my) and (2or), given the discussion in Section 4.1.

Even if there is exact co-positioning of two different utterances in the space - ensuring an overlap of the metaphor and metonymy regions in the space - it does not necessarily follow that there is overlap in the stronger sense defined in the Introduction: namely that there is a phenomenon that at one and the same time qualifies fully as being both metaphor and metonymy (in a sense different from chaining or metaphtonymy, as mentioned in the Introduction). This sort of overlap might not occur because there might be constitutive dimensions that we have not considered. However, the arguments in Section 2.1 do suggest that we should take seriously the idea that referential metaphor is always also a type of metonymy, and the arguments in Section 2.2 suggest that similarity-based Representational metonymy is (often or perhaps always) also a type of metaphor.

Of course, the reason for the snake/line link in (2my) being metonymic can be construed as being different from the reason for its being metaphorical in (2or). The metonymicity could reside just in the fact that the link is crossed for the purpose of achieving the appropriate mental reference, rather than in the intrinsic nature of the link; and the metaphoricity could reside in the use of the link as part of likening one thing to another and/or imaginatively identifying one thing with another. This would make metonymy and metaphor be, by definition, different properties of the use of links, no matter how much these properties coincide in application and no matter what the links are like intrinsically. In this view, the overlap of metaphor and metonymy in the use of a given link is a mixing of two different phenomena, but it is a different sort of mixing from the chaining of two links, one metonymic and the other metaphorical.

The situation as regards intermediacy is different. Recall from the Introduction that intermediacy is the issue of whether there are phenomena that have some of the qualities of both metaphor and metonymy but are not classified as either. Notice first that intermediateness and overlap do not imply each other, and are strongly contrasting concepts. Two types of thing can overlap without there being anything outside both types that are nevertheless close enough to both to qualify as intermediate between them; and two non-overlapping types of thing can have things between them. Even numbers and prime numbers overlap on the number 2, but this does not imply there is anything intermediate between evenness and primeness; and a 30-year old is intermediate between being a teenager and a middle-aged person whereas of course teenagers and middle-aged people have no overlap. However, the question of intermediacy 
versus overlap can be more complicated. The fringes of two categories might overlap and we could say that items within this overlap are intermediate between more central parts of the categories.

Now, although each individual dimension that we have discussed has some similarity to a spectrum or continuum as proposed by other researchers, and the word "spectrum" or "continuum" suggests possibilities intermediate between metaphor and metonymy, our arguments do not necessarily imply intermediate phenomena. This article leaves this issue to future investigation. If we could show that on at least one constitutive dimension there were phenomena intermediate between metaphor and metonymy then the phenomena would necessarily be intermediate in the whole space. The intermediacy on the one dimension would be enough to stop the phenomena qualifying fully as either metaphor or metonymy. But in principle at least there could be phenomena that are intermediate in the whole space but that are not intermediate between them on any one dimension. Indeed, metaphor and metonymy might use largely the same portions of every dimension separately and yet still be completely separate in the whole space and allow intermediate possibilities there, because of complex interactions between the dimensions. ${ }^{5}$

The way in which the dimensions enrich and sharpen the analysis of overlap and intermediacy between metaphor and metonymy is one way in which it is fruitful to consider the dimensions as opposed to confining discussion to the broader concepts of metaphor and metonymy.

\section{3. (Some) metaphor as double metonymy}

One type of theoretical move that considerably muddies the figurative water is to claim that metaphor in general, or some types of metaphor, are actually composed of metonymy in some way. For instance, the analyses of Riemer (2001, 2002) and Barcelona (2000b) indicate that any metaphor whose meaning is construed as transferring features identically from source to target can be viewed as metonymy, because those features can be viewed as metonymically linked to both the source item and the target item. (See also Haser [2005: 25].) In this vein Riemer mentions the view of Group $\mu$ (1981) that metaphor is double synecdoche (therefore double metonymy). That is - with some deviation from Group $\mu$ 's own terminology — there is a metonymy from the source concept to a feature also possessed by the target concept, and from that feature to the target concept. Alternatively, this can be viewed as a metonymy from the source concept up to a shared superordinate category (the category of things that possess the feature in question) and then down to the target concept.

A theoretician is free to regard metaphor as composed of metonymy in some such way, but there is a sense in which it does not really matter - it is a labelling move that leaves undisturbed the important point, namely that certain types of language involve certain types of conceptual link, or collections of links, where individual links may have qualities of similarity, contiguity or both, or may have other qualities; where the assembly of links used may be some 
strange mixture of types; and where different instances of language can structurally and procedurally arrange the links involved in a large number of different ways.

Notice also that casting metaphor as metonymy does not of itself mean that the importance of, say, similarity in metaphor is downgraded. For example, in a double-metonymy view we still have the issue of what particular shared attribute (or set of attributes) or covering abstraction is being used, i.e., what the similarity is. It is just that this similarity is being theoretically structured as being via metonymies involving shared properties or via a covering abstraction. And of course we cannot couple just any two metonymies together to get a metaphor.

\section{Conclusions}

We have seen that several ways in which metaphor and metonymy have been thought to differ do not work, because the alleged differences are fuzzy or are at best only general tendencies. The fuzziness and slipperiness of the differences is even greater than some authors have already considered them to be. In particular, we have argued that distinctions between metaphor and metonymy based on the following issues fail: contiguity versus similarity; source/target links surviving as part of the message; interaction with conceptual compartments; and (in passing) structural correspondence and hypotheticality of source items. While the author's own ATT-Meta theory of metaphor involves imaginary identification, as does blending theory, it is possible that metonymy involves it as well. Not only do the mentioned dimensions not serve individually to distinguish metaphor from metonymy, we have seen evidence that no combination of them does, because different utterances can be at the same position in the multidimensional space; and there is even a case for saying that sometimes the use of a source/target link can be simultaneously metonymic and metaphorical. Some of our arguments echo points made by other authors, but we have added qualitatively new evidence and critique.

Of course, the arguments do not bear upon the distinguishing power of other possible dimensions. Another question is whether our arguments bear against the possibility that there are (proto)typical forms of metaphoricity and metonymicity that can be cleanly distinguished. Haser (2005) argues against even this being possible on the differentiating grounds that have been put forward in Cognitive Linguistics, but the present article leaves the possibility open, partly because it is by no means clear what counts as (proto)typical.

In that metaphor and metonymy involve fuzzily defined ranges of complex combinations of contiguity, similarity, link survival, etc., it is helpful in the interests of more precise, richer, deeper and more liberated analysis to disentangle these properties from each other, even though the individual notions of contiguity, similarity, link survival, etc. are themselves fuzzily defined. We have argued that metaphor and metonymy can each involve types of contiguity and similarity, getting away from tacit, simplistic assumptions that these properties are opposed to each other. By arguing that some metonymy involves similarity in an essential way we encourage attention on investigating just what are the 
forms and extents of similarity that appear in metonymy and metaphor. Again, instead of seeking a way of firmly differentiating metaphor and metonymy through their interaction with conceptual compartments such as domains and frames, we can concentrate on neutrally examining the ways in which metonymy and metaphor stay within or cross between compartments in particular regimes of compartments. We have also seen that the dimensions enrich the analysis of overlap and intermediacy between metaphor and metonymy. In particular, we advance beyond singlespectrum views and bring to light new possibilities for intermediacy. The question of whether more distant regions of the multidimensional space are interesting also arises.

Thus, a major conclusion from the discussion in this article is that instead of worrying about whether some utterance is metaphorical or metonymic, or even about how far the utterance is along a literal/metonymic/metaphorical continuum it is, we should often be asking instead: What degree and type of similarity does it involve, if any? What sort of contiguity does it involve, if any? Does it involve link survival? Is the source item hypothetical, and in what way? Is there any imaginary identification? And so forth. Considering the dimensions in themselves helps to free us from a mindset that seeks clear-cut differences between metaphor and metonymy when these may not exist.

The most radical form this conclusion might take is the eliminativist possibility that the words "metaphor" and "metonymy" are just pragmatically useful labels in approximate discussions, not legitimate foci for detailed technical attention. Ritchie (2006: 11) says that "Metaphor, and figurative language generally, is but a convenient way of identifying and discussing a widely-recognized but fuzzily defined subset of [certain interpretive connections he discusses]." Fauconnier (2009) says that metaphor, metonymy, etc. elude rigorous definition and that these categories do not provide deep insight; that insight comes from looking at the detailed underlying cognitive operations involved, such as blending, and the way they are combined. However, irrespective of whether such eliminativist suggestions are correct, the points made above about the usefulness of the dimensional analysis hold good. 


\section{Notes}

(1) Of course, we might claim that the structuring of the world into, say, containers and contents is itself a mental imposition, and that there is no real world out there. If that is factored in, then the distinction being drawn is between the real, objective world as naively conceived to exist in common-sense as opposed to what even common-sense would concede is imposed on the world by minds.

(2) From notes on the Pastoral symphony by Jan Smaczny for City of Birmingham Symphony Orchestra, England, April 2000.

(3) However, Norrick (1981) does not discuss Representational metonymy.

(4) http://ladynicole.blogspot.com/2005_08_01_archive.html (accessed 3rd July 2008).

(5) This could happen much as with shapes in geometric space. Consider an upright square in 2D space. Split the square on a diagonal and separate the two resulting triangles a little. The points within both triangles involve roughly the same range of horizontal positions and the same range of vertical positions. Yet the triangles do not overlap at all and there are intermediate points. 


\section{References}

Barcelona, Antonio (ed.) 2000a. Metaphor and metonymy at the crossroads: A cognitive perspective. Berlin \& New York: Mouton de Gruyter.

Barcelona, Antonio. 2000b. On the plausibility of claiming a metonymic motivation for conceptual metaphor. In Antonio Barcelona (ed.), Metaphor and metonymy at the crossroads: A cognitive perspective, 31-58. Berlin \& New York: Mouton de Gruyter.

Barcelona, Antonio. 2002. Clarifying and applying the notions of metaphor and metonymy within cognitive linguistics: An update. In René Dirven \& Ralf Pörings (eds.), Metaphor and metonymy in comparison and contrast, 207-277. Berlin \& New York: Mouton de Gruyter.

Barcelona, Antonio. 2004. Metonymy behind grammar: The motivation of the seemingly "irregular" grammatical behavior of English paragon names. In Günter Radden \& Klaus-Uwe Panther (eds.), Studies in linguistic motivation, 357-374. Berlin \& New York: Mouton de Gruyter.

Barnden, John A. 2001. Uncertainty and conflict handling in the ATT-Meta context-based system for metaphorical reasoning. In Varol Akman, Paolo Bouquet, Richmond Thomason \& Roger A. Young (eds.), Modeling and Using Context: Third International and Interdisciplinary Conference (Lecture Notes in Artificial Intelligence 2116), 15-29. Berlin: Springer.

Barnden, John A. 2006. Artificial intelligence, figurative language and cognitive linguistics. In Gitte Kristiansen, Michel Achard, René Dirven \& Francisco J. Ruiz de Mendoza Ibáñez (eds.), Cognitive linguistics: Current applications and future perspectives, 431-459. Berlin \& New York: Mouton de Gruyter.

Barnden, John A., Sheila R. Glasbey, Mark G. Lee \& Alan M. Wallington. 2004. Varieties and directions of interdomain influence in metaphor. Metaphor and Symbol 19(1). 1-30.

Black, Max. 1993 [1979]. More about metaphor. In Andrew Ortony (ed.), Metaphor and thought, 2 nd edn., 19-41. Cambridge \& New York: Cambridge University Press.

Cameron, Lynne. 1999a. Operationalising 'metaphor' for applied linguistic research. In Lynne Cameron \& Graham Low (eds.), Researching and applying metaphor, 1-28. Cambridge \& New York: Cambridge University Press.

Cameron, Lynne. 1999b. Identifying and describing metaphor in spoken discourse data. In Lynne Cameron \& Graham Low (eds.), Researching and applying metaphor, 105-132. Cambridge \& New York: Cambridge University Press. 
Chiappe, Dan L. 1998. Similarity, relevance, and the comparison process. Metaphor and Symbol 13(1). 17-30.

Cooper, David E. 1986. Metaphor. Oxford: Blackwell.

Croft, William. 2002. The role of domains in the interpretation of metaphors and metonymies. In René Dirven \& Ralf Pörings (eds.), Metaphor and metonymy in comparison and contrast, 161-205. Berlin \& New York: Mouton de Gruyter.

Croft, William. 2006. On explaining metonymy: Comments on Peirsman and Geeraerts, "Metonymy as a prototypical category." Cognitive Linguistics, 17(3). 317-326.

Croft, William \& D. Alan Cruse. 2004. Cognitive linguistics. Cambridge \& New York: Cambridge University Press.

Dirven, René. 2002. Metonymy and metaphor: Different mental strategies of conceptualization. In René Dirven \& Ralf Pörings (eds.), Metaphor and metonymy in comparison and contrast, 75-111. Berlin \& New York: Mouton de Gruyter.

Dirven, René \& Ralf Pörings (eds.). 2002. Metaphor and metonymy in comparison and contrast. Berlin \& New York: Mouton de Gruyter.

Fass, Dan. 1997. Processing metaphor and metonymy. Greenwich, Connecticut: Ablex.

Fauconnier, Gilles. 2009. Generalized integration networks. In Vyvyan Evans \& Stéphanie Pourcel (eds.), New directions in cognitive linguistics, 147-160. Amsterdam: John Benjamins.

Fauconnier, Gilles \& Mark Turner. 1998. Conceptual integration networks. Cognitive Science, 22(2). $133-187$.

Feyaerts, Kurt. 2000. Refining the Inheritance Hypothesis: Interaction between metaphoric and metonymic hierarchies. In Antonio Barcelona (ed.), Metaphor and metonymy at the crossroads: A cognitive perspective, 59-78. Berlin \& New York: Mouton de Gruyter.

Geeraerts, Dirk. 2002. The interaction of metaphor and metonymy in composite expressions. In René Dirven \& Ralf Pörings (eds.), Metaphor and metonymy in comparison and contrast, 435-465. Berlin \& New York: Mouton de Gruyter.

Gibbs, Ray W., Jr. 1990. Comprehending figurative referential descriptions. Journal of Experimental Psychology: Learning, Memory and Cognition 16(1). 56-66. 
Gibbs, Ray W., Jr. 1999. Researching metaphor. In Lynne Cameron \& Graham Low (eds.), Researching and Applying Metaphor, 29-47. Cambridge \& New York: Cambridge University Press.

Goatly, Andrew. 1997. The language of metaphors. London and New York: Routledge.

Goodman, Nelson. 1968. Languages of art: An approach to a theory of symbols. Indianapolis: Bobbs-Merrill.

Goossens, Louis. 1990. Metaphtonymy: The interaction of metaphor and metonymy in expressions for linguistic action. Cognitive Linguistics 1. 323-340.

Glucksberg, S. 2001. Understanding figurative language. Oxford \& New York: Oxford University Press.

Glucksberg, Sam \& Boaz Keysar. 1990. Understanding metaphorical comparisons: Beyond similarity. Psychological Review, 97(1). 3-18.

Grady, Joseph E. 1997. THEORIES ARE BUILDINGS revisited. Cognitive Linguistics 8(4). 267-290.

Group $\mu$. 1981. A general rhetoric. Baltimore and London: The John Hopkins University Press.

Haser, Verena. 2005. Metaphor, metonymy and experientialist philosophy: Challenging cognitive semantics. Berlin \& New York: Mouton de Gruyter.

Indurkhya, Bipin. 1992. Metaphor and cognition: An interactionist approach. Dordrecht: Kluwer.

Jakobson, Roman. 2002 [1956]. The metaphoric and metonymic poles. In René Dirven \& Ralf Pörings (eds.), Metaphor and metonymy in comparison and contrast, 41-47. Berlin \& New York: Mouton de Gruyter. Reprinted with added abstract by René Dirven from Roman Jakobson \& M. Halle (eds.) (1971 [1956]), Fundamentals of Language 2, 90-96. The Hague \& Paris: Mouton.)

Kittay, Eva F. 1989. Metaphor: Its cognitive force and linguistic structure. (Paperback ed.) Oxford: Clarendon Press.

Kövecses, Zoltán. 1990. Emotion concepts. Berlin \& New York: Springer.

Kövecses, Zoltán. 2002. Metaphor: A practical introduction. Oxford \& New York: Oxford University Press.

Lakoff, George. 1993. The contemporary theory of metaphor. In Andrew Ortony (ed.), Metaphor and Thought, 2nd edn., 202-251. Cambridge and New York: Cambridge University Press.

Lakoff, George \& Mark Turner. 1989. More than cool reason: A field guide to poetic metaphor. Chicago: University of Chicago Press. 
Langlotz, Andreas. 2006. Idiom creativity: A cognitive-linguistic model of idiom-representation and idiom-variation in English. Amsterdam \& Philadelphia: John Benjamins.

Lodge, David. 1977. The modes of modern writing: Metaphor, metonymy and the typology of modern literature. London: Edward Arnold; Ithaca, NY: Cornell University Press.

Moore, Kevin E. 2006. Space-to-time mappings and temporal concepts. Cognitive Linguistics 17(2). 199-244.

Norrick, Neal R. 1981. Semiotic principles in semantic theory. Amsterdam: John Benjamins.

Nunberg, Geoffrey. 1978. The pragmatics of reference. Bloomington, IN: Indiana University Linguistics Club.

Nunberg, Geoffrey. 1995. Transfers of meaning. Journal of Semantics 12(2). 109-132.

Panther, Klaus-Uwe. 2006. Metonymy as a usage event. In Gitte Kristiansen, Michel Achard, René Dirven \& Francisco J. Ruiz de Mendoza Ibáñez (eds.), Cognitive linguistics: Current applications and future perspectives, 147-185. Berlin \& New York: Mouton de Gruyter.

Paradis, Carita. 2004. Where does metonymy stop? Senses, facets, and active zones. Metaphor and Symbol 19(4). 245-264.

Peirsman, Yves \& Dirk Geeraerts. 2006. Metonymy as a prototypical category. Cognitive Linguistics 17(3). 269-316.

Pragglejaz Group 2007. MIP: A method for identifying metaphorically used words in discourse. Metaphor and Symbol 22(1). 1-39.

Radden, Günter. 2002. How metonymic are metaphors? In René Dirven \& Ralf Pörings (eds.), Metaphor and metonymy in comparison and contrast, 407-434. Berlin \& New York: Mouton de Gruyter.

Radden, Günter \& Zoltán Kövecses. 1999. Towards a theory of metonymy. In Klaus-Uwe Panther \& Günter Radden, Metonymy in language and thought, 17-59. Amsterdam \& Philadelphia: John Benjamins.

Radman, Zdravko. 1997. Difficulties with diagnosing the death of a metaphor. Metaphor and Symbol 12(2). 149-157.

Riemer, Nick. 2001. Remetonomyzing metaphor: Hypercategories in semantic extension. Cognitive Linguistics 12(4). $379-401$.

Riemer, Nick. 2002. When is a metonymy no longer a metonymy. In René Dirven \& Ralf Pörings (eds.), Metaphor and metonymy in comparison and contrast, 379-406. Berlin \& New York: Mouton de Gruyter. 
Ritchie, L. David. 2006. Context and connection in metaphor. Basingstoke and New York: Palgrave Macmillan.

Ruiz de Mendoza Ibáñez, Francisco J. 1999. From semantic underdetermination via metaphor and metonymy to conceptual interaction. Paper No. 492, LAUD Linguistic Agency, SERIES A: General \& Theoretical Papers.

Ruiz de Mendoza Ibáñez, Francisco J. \& Olga I. Díez Velasco. 2002. Patterns of conceptual interaction. In René Dirven \& Ralf Pörings (eds.), Metaphor and metonymy in comparison and contrast, 489-532. Berlin \& New York: Mouton de Gruyter.

Stern, Josef. 2000. Metaphor in context. Cambridge, MA and London, UK: Bradford Books, MIT Press.

Turner, Mark \& Gilles Fauconnier. 1995. Conceptual integration and formal expression. Metaphor and Symbolic Activity 10(3). 183-204.

Turner, Mark \& Gilles Fauconnier. 2000. Metaphor, metonymy, and binding. In Barcelona (2000a), 133-145.

Turner, Mark \& Gilles Fauconnier. 2002. Metaphor, metonymy, and binding. In René Dirven \& Ralf Pörings (eds.), Metaphor and metonymy in comparison and contrast, 469-487. Berlin \& New York: Mouton de Gruyter.

Ullmann, Stephen. 1962. Semantics: An introduction to the science of meaning. Oxford: Blackwell.

Warren, Beatrice. 1999. Aspects of referential metonymy. In Klaus-Uwe Panther \& Günter Radden, Metonymy in language and thought, 121-135. Amsterdam \& Philadelphia: John Benjamins.

Warren, Beatrice. 2002. An alternative account of the interpretation of referential metonymy and metaphor. In René Dirven \& Ralf Pörings (eds.), Metaphor and metonymy in comparison and contrast, 113-130. Berlin \& New York: Mouton de Gruyter.

Warren, Beatrice. 2006. Referential metonymy. Scripta Minora of the Royal Society of Letters at Lund, 2003-2004: 1. Stockholm: Almqvist \& Wiksell International.

Wee, Lionel. 2006. Proper names and the theory of metaphor. Journal of Linguistics 42. 355-371. 